\title{
Performance of the Polymer Electrolyte Membranes Impregnated with Some Room-temperature Ionic Liquids at Elevated Temperature
}

\author{
Arata Goto, Yusuke Kawagoe, Yasushi Katayama, ${ }^{*}$ and Takashi Miura \\ Department of Applied Chemistry, Faculty of Science and Technology, Keio University (Hiyoshi 3-14-1, Kohoku-ku, \\ Yokohama 223-8522, Japan)
}

Received August 17, 2006 ; Accepted October 28, 2006

\begin{abstract}
The Nafion membrane impregnated with various room-temperature ionic liquids have been prepared and characterized as the electrolytes for polymer electrolyte fuel cells (PEFCs) operated at elevated temperature (100 $200{ }^{\circ} \mathrm{C}$ ). The continuous proton transportation in the membrane was confirmed under dry hydrogen atmosphere at $160^{\circ} \mathrm{C}$. The ionic conductivity of the membrane was determined by both $\mathrm{DC}$ and $\mathrm{AC}$ measurements under dry hydrogen atmosphere and found to reach the order of $10^{-2} \mathrm{~S} \mathrm{~cm}^{-1}$ at $200^{\circ} \mathrm{C}$ without humidification. It is suggested that the high ionic conductivity of the membrane is caused mainly by free ionic liquids in the membranes. The continuous operation of the PEFC using the membrane was found to be possible without humidification at $120^{\circ} \mathrm{C}$. However, the overpotential at the cathode was found to be large compared with the anode probably due to the sluggish electrode reaction and/or the slow diffusion of HTFSI in the membranes.
\end{abstract}

Key Words : PEFCs, Polymer Electrolyte, Ionic Liquid

\section{Introduction}

Polymer electrolyte fuel cells including direct alcohol fuel cells (DAFCs) are attracting much attention as the power sources for mobile instruments and vehicles. Perfluorocarbon sulfonic acid polymer membranes, such as Nafion ${ }^{\circledR}$, Flemion ${ }^{\circledR}$ and Aciplex ${ }^{\circledR}$ are widely used in these fuel cells because of their high protonic conductivity and chemical stability. The protonic conduction in these membranes is achieved by dissociation of protons from sulfonic acid groups in the presence of water. ${ }^{1)}$ Therefore, the protonic conductivity decreases drastically at elevated temperatures, especially over $100{ }^{\circ} \mathrm{C}$, because of evaporation of water. On the other hand, the operation of these fuel cells at elevated temperatures is desirable since the electrode kinetics is expected to be improved at higher temperatures. In particular, the poisoning of platinum catalysts by carbon monoxide, which forms as the impurity of reformed hydrogen gas or the intermediate product of alcohol oxidation, at anodes is also expected to be diminished at the temperature near $200{ }^{\circ} \mathrm{C}$. Practically, it is possible to suppress the evaporation of water in the conventional polymer electrolyte membranes at elevated temperatures by humidification and pressurization, which make the system large and complicated. Therefore, it is demanded to develop a new class of electrolyte membranes which can be used at elevated temperatures without humidification.

One of the approaches for developing such membranes is to use room-temperature ionic liquids, which consist of only ions without molecular solvents. Ionic liquids have several favorable properties, such as negligible vapor pressure, high thermal and chemical stability, low melting point and acceptable ionic conductivity. Recently, it has been reported that the polymer electrolytes impregnated with ionic liquids instead of water can realize high ionic conduction even above $100{ }^{\circ} \mathrm{C}$. Fuller et al. reported the ionic conductivity of the Nafion membrane impregnated with 1-ethyl-3-methylimidazolium tetrafluoroborate or 1-ethyl-3-methylimidazolium trifluoromethylsulfonate reaches $1.2 \times 10^{-3} \mathrm{~S} \mathrm{~cm}^{-1}$ at $125^{\circ} \mathrm{C}^{2)}$ Doyle et al. measured the ionic conductivity of perfluoro ionometric membranes impregnated with $1-n$-butyl-3-methylimidazolium tetrafluoroborate or 1-n-butyl-3-methylimidazolium trifluoromethylsulfonate in the temperature range from 100 to $200{ }^{\circ} \mathrm{C}$ and discussed about dependence of the ionic conductivity on the property of membranes or ionic liquids. ${ }^{3)}$ Sun et al. reported about Nafion or Teflon membrane impregnated with ionic liquids, ionic liquidacid mixtures of ionic liquid and acids or other molecular liquids. ${ }^{4}$ In these studies, the ionic conductivity of the membranes was measured by only AC method. Furthermore, these reports did not refer to the mechanism of ionic conduction and proton transportation in the membranes.

In this study, the ionic conductivity of Nafion membranes impregnated several room-temperature ionic liquids has been measured by both DC and AC methods under dry hydrogen atmosphere at $100 \sim 200^{\circ} \mathrm{C}$. Various TFSI--based ionic liquids were selected systematically to investigate the effect of the difference of ionic liquid on the ionic conductivity of the membrane. Moreover, the mechanism of ionic conduction and proton transportation in the membranes was presumed based on these measurements. In addition, the operation of the PEFC using the membrane was also demonstrated at $120^{\circ} \mathrm{C}$ without humidification. 


\section{Experimental}

\section{1 Synthesis of room-temperature ionic liquids}

Room-temperature ionic liquids used in this study are EMITFSI, BMITFSI, MPPTFSI, BMPTFSI, TMHATFSI, BMITf and $\mathrm{BMIPF}_{6}\left(\mathrm{EMI}^{+}=1\right.$-ethyl-3-methylimidazolium, $\mathrm{BMI}^{+}=1$ - $n$-butyl-3-methylimidazolium, $\mathrm{MPP}^{+}=1$ methyl -l- $n$-propylpyrrolidinium, $\mathrm{BMP}^{+}=1$-methyl-l- $n$ butylpyrrolidinium, $\mathrm{TMHA}^{+}=$tri(methyl)- $n$-hexylammonium, $\mathrm{TFSI}^{-}=$bis(trifluoromethylsulfonyl)imide, $\mathrm{Tf}^{-}=$trifluoromethylsulfonate, $\mathrm{PF}_{6}{ }^{-}=$hexafluorophosfate).

1-Ethyl-3-methylimidazolium and 1- $n$-butyl-3-methylimidazolium bromide were prepared by reacting 1methylimidazole (Tokyo Kasei, purity $99 \%$ ) with ethyl bromide (Tokyo Kasei, purity $98 \%$ ) and $n$-butyl bromide (Tokyo Kasei, purity 98\%), respectively, according to the literature. ${ }^{5)}$ 1-Methy-1- $n$-propylpyrrolidinium and 1- $n$ butyl-1-methylpyrrolidinium bromide were prepared by interacting 1-methylpyrroridine with n-propyl bromide (Tokyo Kasei, purity $98 \%$ ) and $n$-butyl bromide, respectively, as described elesewhere. ${ }^{6)}$ Tri(methyl)-n-hexylammonium bromide ( Tokyo Kasei, purity $98 \%$ ) was used after recrystallization and vacuum drying. These bromide salts were handled and stored in an argon-filled glove box with a continuous gas purification apparatus (Miwa Seisakujo, DB0-1K-SH). The concentrations of $\mathrm{H}_{2} \mathrm{O}$ and $\mathrm{O}_{2}$ in the glove box were kept under $800 \mathrm{ppb}$ and 1 ppm, respectively.

The TFSI--based ionic liquids were prepared by the metathesis reaction of the bromide salts with LiTFSI (Kanto Denka Kogyo, purity $>99.9 \%$ ) in deionized water. The ionic liquids were extracted into dichloromethane, separated by evaporation and finally dried under vacuum at $\sim 140{ }^{\circ} \mathrm{C}$ for longer than 24 hours.

BMITf was prepared by potentiometric titration of the aqueous solution of BMIBr by a AgTf aqueous solution with a $\mathrm{Ag}$ electrode and $\mathrm{Ag} / \mathrm{AgCl}$ reference electrode. AgTf was obtained by reacting $\mathrm{Ag}_{2} \mathrm{O}$ (Aldrich, purity 99\%) and HTf aqueous solution (Wako pure chemical industries, Ltd., purity $98 \%$ ). After removing AgBr precipitate by filtration, BMITf was separated by evaporation and dried under vacuum at $\sim 140^{\circ} \mathrm{C}$ for longer than 24 hours.

$\mathrm{BMIPF}_{6}$ was prepared by interacting $\mathrm{BMIBr}$ with an equimolar amount of $\mathrm{KPF}_{6}$ (Aldlich, purity 98\%) in deionized water at room-temperature, followed by extraction into dichloromethane and vacuum drying at $120{ }^{\circ} \mathrm{C}$ for longer than 24 hours.

\section{2 Impregnation of Nafion membranes with ionic liquids}

Nafion 117 (Aldrich) was boiled in 3 wt.\% hydrogen peroxide for 1 hour to eliminate organic contaminants, followed by rinsing with pure water and boiling in pure water for 1 hour. Then, the membrane was boiled in $1 \mathrm{M}$ sulfuric acid for 1 hour for protonation, followed by rinsing with pure water and boiling in pure water for 1 hour. The membrane was dried under vacuum at $80^{\circ} \mathrm{C}$ for longer than 48 hours and immersed in ionic liquids under vacuum at $100 \sim 180^{\circ} \mathrm{C}$ for longer than 20 hours. The amount of an ionic liquid in the membrane, $X_{\mathrm{IL}}\left(\mathrm{mmol} \mathrm{g}^{-1}\right)$ was represented as the moles of the ionic liquid per $1 \mathrm{~g}$ of the dried membrane, defined as follows.

$$
X_{\mathrm{IL}}=\frac{w-w_{\mathrm{d}}}{M \cdot w_{\mathrm{d}}}
$$

where $w(\mathrm{~g})$ is the weight of the membrane impregnated with the ionic liquid, $w_{\mathrm{d}}(\mathrm{g})$ is the weight of the dried membrane and $M\left(\mathrm{~g} \mathrm{mmol}^{-1}\right)$ is the formula weight of the ionic liquid.

The thermal stability of the membranes were examined with TG-DTA (Rigaku, Thermo plus TG 8120) and DSC (Rigaku, Thermo plus DSC 8230).

\section{3 Electrochemical measurements}

The conductivity of the membrane was measured with a four-probe cell consisting of two inner platinum needle electrodes $(0.3 \mathrm{~mm} \phi)$ and two outer platinum mesh electrodes $(0.07 \mathrm{~mm} \phi$ wire, 55 mesh, geometric area $=0.4$ $\mathrm{cm}^{2}$ ). The intervals of the inner and outer electrodes are 10 and $30 \mathrm{~mm}$, respectively. The cell was placed in a vessel with a gas inlet and outlet. Dry hydrogen or nitrogen was fed to the vessel at $50 \mathrm{~cm}^{3} \mathrm{~min}^{-1}$. The conductivity was calculated from the voltage drop between the inner electrodes with feeding DC $(0.2 \sim 20 \mu \mathrm{A})$ or $\mathrm{AC}(1 \mu \mathrm{A}, 10$ $\mathrm{mHz} \sim 20 \mathrm{kHz}$ ) to the outer electrodes.

The operation test of the fuel cell using the membrane was conducted with a single fuel cell apparatus (EFC0501SP, ElectroChem, Inc.) with the MEA composed of the membrane sandwiched with platinum mesh electrodes (100 mesh, geometric area $\left.=5 \mathrm{~cm}^{2}\right)$. Dry hydrogen or oxygen gas was fed to the cell at a flow rate of $50 \mathrm{~cm}^{3}$ $\min ^{-1}$. A platinum reference electrode was used for measurement of overpotentials at the anode and cathode.

All the electrochemical measurements were conducted with computerized potentio/galvanostat (Hokuto Denko, HZ3000).

\section{Results and Discussion}

\section{1 Characterization of the membranes impregnated} with ionic liquids

Colorless, transparent and flexible membranes were obtained by immersing dried Nafion membranes in ionic liquids under vacuum. It is essential to eliminate gases remaining in the dried membranes under vacuum in order to introduce sufficient amounts of ionic liquids into the membranes. The amount of each ionic liquid in the membrane, $X_{\mathrm{IL}}$, was in the range from 0.5 to $3.9 \mathrm{mmol} \mathrm{g}^{-1}$ depending on the temperature and period of the immersion. In general, $X_{\text {IL }}$ tends to increase with an increase in the immersion temperature. No leakage of the ionic liquid was observed when the membrane was stored at room-temperature under atmospheric pressure for a few weeks. In this paper, the Nafion membranes containing water and an ionic liquid are represented as $\mathrm{H}_{2} \mathrm{O}$ /Nafion and (the abbreviation of the ionic liquid, i.e. BMPTFSI) /Nafion, respectively.

Figure 1 shows the DSC curves of dried Nafion and

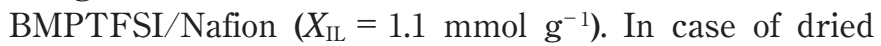
Nafion, a peak corresponding to glass transition was observed at $\sim 130^{\circ} \mathrm{C}$. However, no glass transition was observed for BMPTFSI/Nafion in the examined temperature range, suggesting the ionic liquid acts as a plasticiz- 
er. In fact, the membranes impregnated with ionic liquids were softer and more flexible than $\mathrm{H}_{2} \mathrm{O}$ /Nafion at room-temperature. The thermal decomposition temperatures of the dried Nafion, BMPTFSI/Nafion and neat BMPTFSI were examined by thermal gravimetry. The TG curve of BMPTFSI/Nafion is overlapped with that of dried Nafion while the decomposition of neat BMPTFSI begins at the temperature higher than those of the membranes, as shown in Fig. 2. Since the thermal decomposition of Nafion is reported to start above $350^{\circ} \mathrm{C}$, ${ }^{7}$ the thermal stability of BMPTFSI/Nafion is reflecting that of Nafion. The appearance of BMPTFSI/Nafion was unchanged before and after heating at 150 or $200{ }^{\circ} \mathrm{C}$ under dry nitrogen for 15 minutes. However, BMPTF-

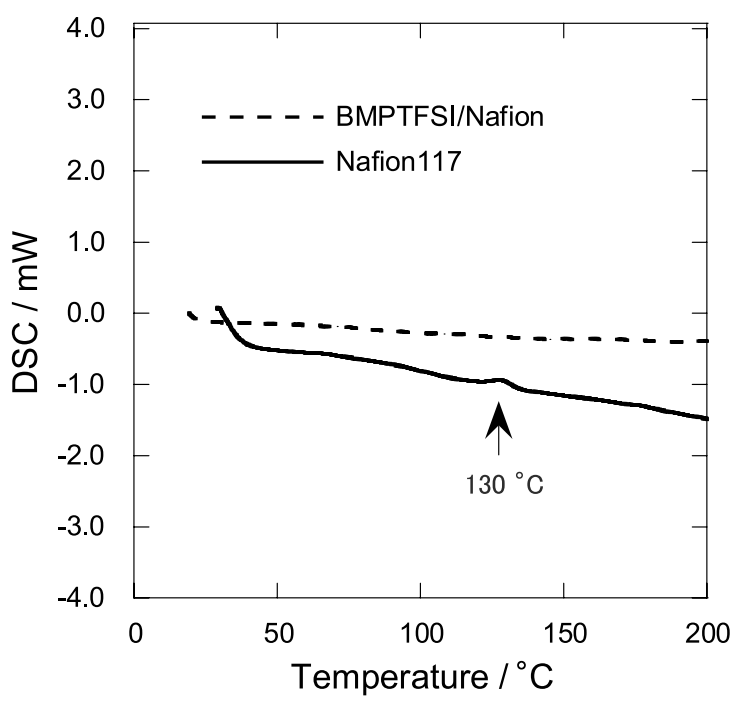

Fig. 1 DSC curves of a dried Nafion membrane $\left(\mathrm{H}^{+}\right.$type) and BMPTFSI/Nafion $\left(X_{\mathrm{IL}}=1.1 \mathrm{mmol} \mathrm{g}^{-1}\right)$. Scan rate : $5{ }^{\circ} \mathrm{C}$ $\min ^{-1} . \mathrm{N}_{2}$ atomosphere.

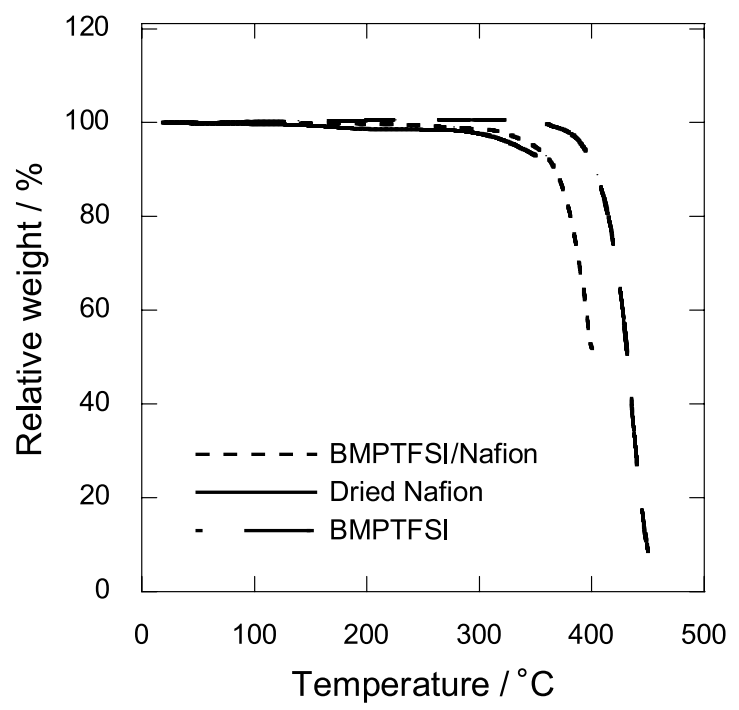

Fig. 2 TG curves of a dried Nafion membrane $\left(\mathrm{H}^{+}\right.$type), BMPTFSI/Nafion $\left(X_{\mathrm{IL}}=1.1 \mathrm{mmol} \mathrm{g}^{-1}\right)$ and neat BMPTFSI. Scan rate : $5^{\circ} \mathrm{C} \min ^{-1} . \mathrm{N}_{2}$ atmosphere.
SI/Nafion completely melted at $250{ }^{\circ} \mathrm{C}$. Therefore, it is found that the Nafion membranes impregnated with ionic liquids can be used up to $\sim 200{ }^{\circ} \mathrm{C}$ without thermal degradation.

\section{2 Conductivity measurements}

It is essential to confirm whether protons are transported electrochemically in the Nafion membranes impregnated with ionic liquids in order to apply these membranes for the electrolytes of fuel cells. Figure 3 shows the current flowing between two platinum electrodes attached to a strip of BMPTFSI/Nafion under dry hydrogen or nitrogen atmosphere at $160^{\circ} \mathrm{C}$. A constant voltage of $500 \mathrm{mV}$ was applied between the electrodes. A continuous current was observed under dry hydrogen atmosphere while no current flowed under dry nitrogen atmosphere, indicating the electric conduction based on proton transportation occurs above $100{ }^{\circ} \mathrm{C}$ without humidification.

Figure 4 shows the conductivities of the Nafion membranes containing different amounts of BMPTFSI. The conductivity measured by $\mathrm{AC}$ was consistent with that measured by DC in all cases. The highest conductivity reached the order of $10^{-2} \mathrm{~S} \mathrm{~cm}^{-1}$ at $200^{\circ} \mathrm{C}$. The conductivity increased with an increase in $X_{\mathrm{IL}}$, suggesting the measured conductivity is determined not only by proton transportation in the membrane but also by the ionic conduction of the ionic liquid itself. Figure 5 shows the conductivities of the Nafion membranes impregnated with the TFSI--based ionic liquids composed of different cations. The membranes having nearly the same $X_{\mathrm{IL}}$ were selected since the conductivity depends on $X_{\mathrm{IL}}$ as described above. It is obvious that the conductivity of the membrane depends on the kind of cation. Figure 6 shows the conductivities of the Nafion membranes impregnated with the $\mathrm{BMI}^{+}$-based ionic liquids composed of $\mathrm{TFSI}^{-}$and $\mathrm{PF}_{6}^{-}$. The data for BMITf/Nafion were not shown in Fig. 6 since the membrane impregnated with BMITf having $X_{\mathrm{IL}}$ of $1.6 \sim 1.7$ could not be obtained. The

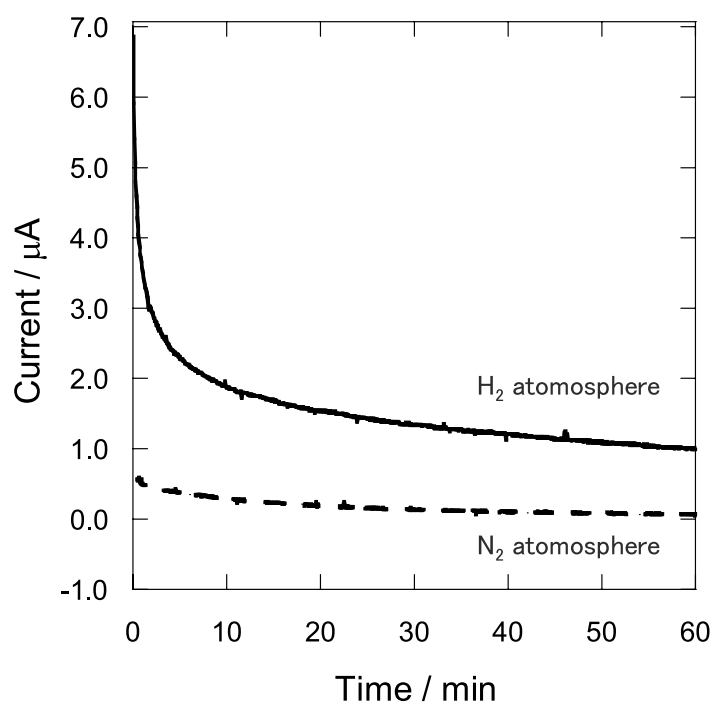

Fig. 3 Direct current observed during potentiostatic polarization for BMPTFSI/Nafion $\left(X_{\mathrm{IL}}=2.7 \mathrm{mmol} \mathrm{\textrm {g } ^ { - 1 } )}\right.$ under dry hydrogen and nitrogen atmosphere at $160{ }^{\circ} \mathrm{C}$. 


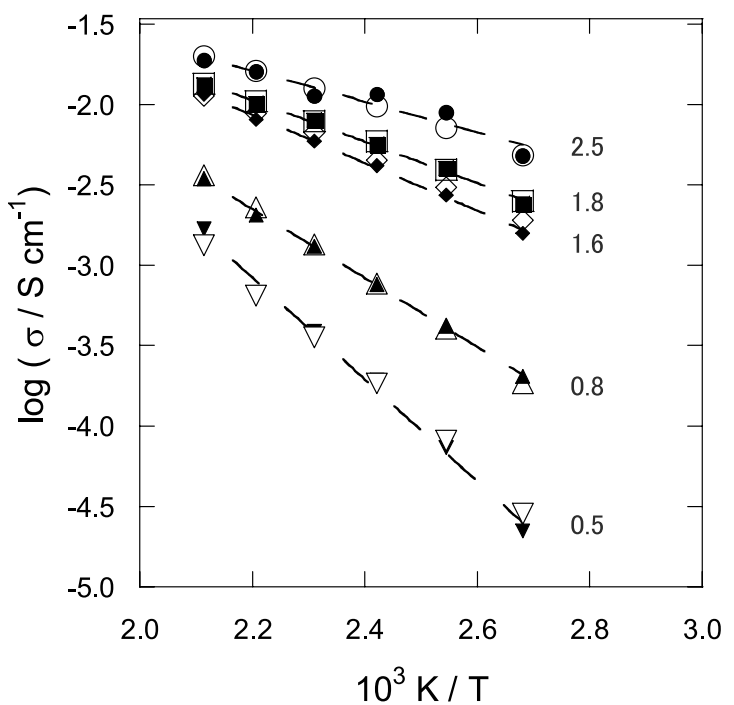

Fig. 4 Conductivity of BMPTFSI/Nafion under dry hydrogen atmosphere measured by $\mathrm{AC}$ (open) and DC (closed) method. $X_{\mathrm{IL}}$ was given in $\mathrm{mmol} \mathrm{g}^{-1}$.

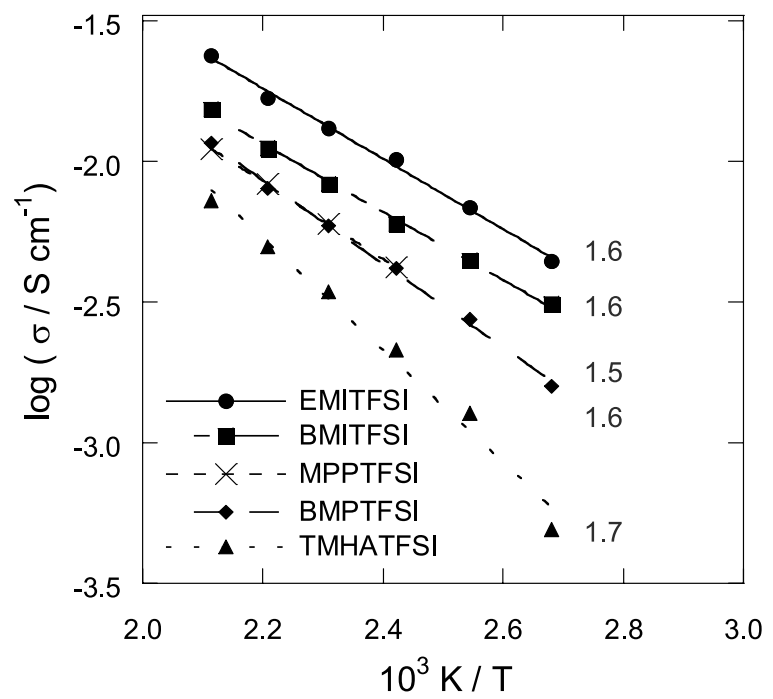

Fig. 5 Conductivity of the Nafion membrane impregnated with some $\mathrm{TFSI}^{-}$-based ionic liquids under dry hydrogen atmosphere measured by DC method. $X_{\mathrm{IL}}$ was given in mmol g ${ }^{-1}$

ionic conductivity of the BMITFSI/Nafion membrane was higher than that of the $\mathrm{BMIPF}_{6} / \mathrm{Nafion}$ membrane, suggesting the ionic conductivity of the membrane is also dependent on the kind of anion. Table 1 lists the conductivity and viscosity of the ionic liquids examined in this study. ${ }^{8-13)}$ The order of the conductivity of the $\mathrm{TFSI}^{-}$-based ionic liquids is $\mathrm{EMI}^{+}>\mathrm{BMI}^{+}>\mathrm{MPP}^{+}>$ $\mathrm{BMP}^{+}>\mathrm{TMHA}^{+}$, which is consistent with that of the membranes. The order of the conductivities of BMITF$\mathrm{SI} / \mathrm{Nafion}$ and $\mathrm{BMIPF}_{6} /$ Nafion also coincides with that of neat ionic liquids. Thus, the ionic conductivity of the membranes is considered to be determined by that of the neat ionic liquids.

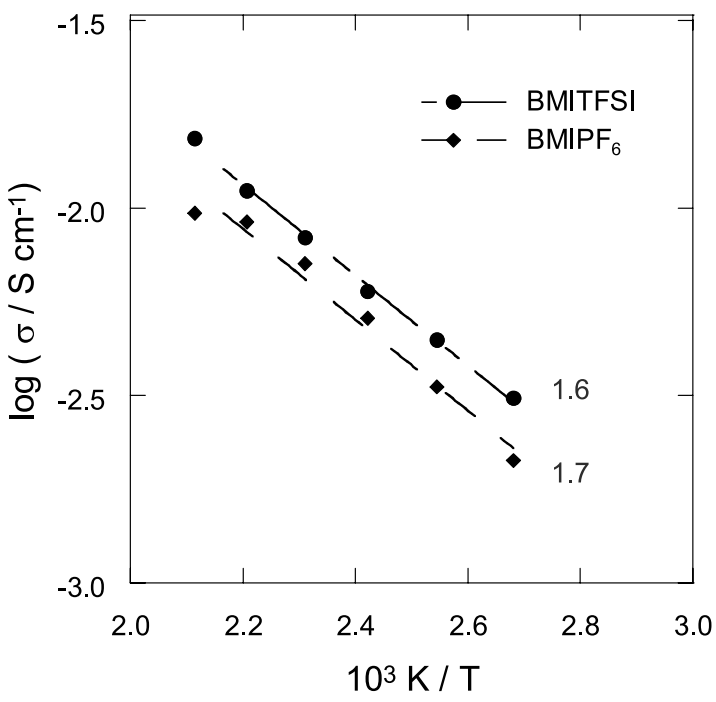

Fig. 6 Conductivity of the Nafion membrane impregnated with some $\mathrm{BMI}^{+}$-based ionic liquids under dry hydrogen atmosphere measured by DC method. $X_{\text {IL }}$ was given in mmol $\mathrm{g}^{-1}$.

Table 1 Viscosity and conductivity of the ionic liquids at $25^{\circ} \mathrm{C}$. $\left(*\right.$ : at $20^{\circ} \mathrm{C}, * *$ : at $\left.30{ }^{\circ} \mathrm{C}\right)$

\begin{tabular}{|c|c|c|c|c|}
\hline & $\begin{array}{c}\text { System } \\
25{ }^{\circ} \mathrm{C}\end{array}$ & $\begin{array}{l}\text { State at } \\
/ \mathrm{mPa} \mathrm{s}\end{array}$ & $\begin{array}{l}\text { Coductivity } \\
/ \mathrm{mS} \mathrm{cm}^{-1}\end{array}$ & Ref. \\
\hline EMITFSI & liquid & $34^{*}$ & $8.8^{*}$ & 8 \\
\hline BMITFSI & liquid & $52 *$ & $3.9 *$ & 8 \\
\hline \multirow[t]{2}{*}{ MPPTFSI } & liquid & 63 & 1.4 & 9 \\
\hline & & 59 & 3.2 & This work \\
\hline \multirow[t]{2}{*}{ BMPTFSI } & liquid & 91.7 & 2.88 & This work \\
\hline & & 85 & 2.2 & 9 \\
\hline TMHATFSI & liquid & 153 & 0.43 & 10 \\
\hline BMITf & liquid & $90 *$ & $3.7 *$ & 8 \\
\hline \multirow[t]{4}{*}{$\mathrm{BMIPF}_{6}$} & liquid & $330 *$ & - & 11 \\
\hline & & $286^{*}$ & - & 12 \\
\hline & & 207 & - & 12 \\
\hline & & $312 * *$ & $1.9 * *$ & 13 \\
\hline
\end{tabular}

\section{3 A proposed mechanism of the proton trans-} portation

It is found that the Nafion membrane impregnated with an ionic liquid can transport protons at the temperature higher than $100{ }^{\circ} \mathrm{C}$ without humidification. However, the proton transportation in this membrane is unlikely to be explained by the Grotthuss mechanism since the apparent conductivity of the membrane is comparable to the conductivity of the neat ionic liquid containing no proton source. Thus, it is necessary to consider an appropriate model for this membrane. Here, BMPTFSI is employed as an example. The amount of $-\mathrm{SO}_{3} \mathrm{H}$ groups in $1 \mathrm{~g}$ of the dried membrane is estimated to be $0.91 \mathrm{mmol}$ according to the equivalent weight of Nafion117, $1100 \mathrm{~g} \mathrm{eq}^{-1}$. Thus, $X_{\mathrm{IL}}$ is required to exceed 
$0.91 \mathrm{mmol} \mathrm{g}^{-1}$ in order to dissociate all the $-\mathrm{SO}_{3} \mathrm{H}$ groups in the membrane when the following reaction is assumed.

$$
-\mathrm{SO}_{3} \mathrm{H}+\mathrm{TFSI}^{-} \rightarrow-\mathrm{SO}_{3}{ }^{-}+\mathrm{HTFSI}
$$

where HTFSI is reported not to dissociate in TFSI ${ }^{-}$based ionic liquids. ${ }^{14)}$ If $X_{\mathrm{IL}}$ is less than $0.91 \mathrm{mmol} \mathrm{g}^{-1}$, it is expected that a part of $-\mathrm{SO}_{3} \mathrm{H}$ groups are not dissociated and that the system can be regarded as a cation $\left(\mathrm{BMP}^{+}\right)$ conductive polymer with neutral HTFSI. This situation can be verified in Fig. 4, where the conductivity of the BMPTFSI/Nafion decreased drastically when $X_{\mathrm{IL}}$ is less than $0.91 \mathrm{mmol} \mathrm{g}^{-1}$. On the other hand, if when $X_{\mathrm{IL}}$ is larger than $0.91 \mathrm{mmol} \mathrm{g}^{-1}$, the membrane contains free $\mathrm{BMP}^{+}$ and $\mathrm{TFSI}^{-}$, which are regarded as a supporting electrolyte. Since the increase in the apparent volume of the membrane was very small at $X_{\mathrm{IL}}>0.91 \mathrm{mmol} \mathrm{g}^{-1}$, the concentration of the supporting electrolyte in the membrane increases with an increase in $X_{\mathrm{IL}}$, leading to the increase of the apparent conductivity of the membrane. On the other hand, the conductivity measured by AC method is close to that measured by DC method probably because the ionic conduction in the membrane is caused by free $\mathrm{BMP}^{+}$and $\mathrm{TFSI}^{-}$while HTFSI is generated at the anode, transferred by the concentration gradient of HTFSI and consumed at the cathode. Therefore, the apparent proton conductivity is expected to be determined by the diffusivity of HTFSI in the membrane. Figure 7 illustrates the proposed model of the proton transportation in BMPTFSI/Nafion. The decay of the electrolytic current with time under hydrogen atmosphere as shown in Fig. 1 could be explained by the growth of the diffusion layer at the electrodes assuming this model.

In the membranes impregnated with TFSI--based ionic liquids, the loss of HTFSI is anticipated at high temperature since HTFSI is known to sublime above $100{ }^{\circ} \mathrm{C}$. However, the TG curve of BMPTFSI/Nafion in Fig. 2 shows little weight loss up to $200{ }^{\circ} \mathrm{C}$, suggesting the evaporation of HTFSI is suppressed in this membrane.

The similar model may be assumed for the membranes impregnated the ionic liquids composed of such anions as $\mathrm{Tf}^{-}$and $\mathrm{PF}_{6}{ }^{-}$since protons are considered to associate with anionic species.

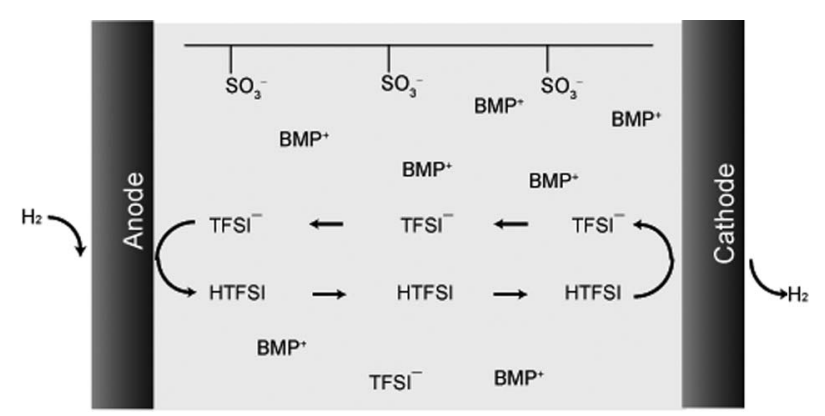

Fig. 7 The schematic illustration of a proposed mechanism for the proton transportation in BMPTFSI/Nafion.

\section{4 Operation of a fuel cell using the membrane}

It is desirable to use an ionic liquid showing high ionic conductivity to make the conductivity of the membrane higher. TFSI ${ }^{-}$is one of the most promising anions since TFSI $^{-}$-based ionic liquids show lower melting point and higher ionic conductivity than the ionic liquids composed of other anionic species. On the other hand, the ionic liquids composed of imidazolium cations show high ionic conductivity. However, they are not suitable for the electrolytes for fuel cells since the imidazolium cations are expected to react with nucleophilic regents like $\mathrm{O}_{2}{ }^{-}$and $\mathrm{OH}^{-}$, which form as intermediate products of oxygen reduction. ${ }^{5)}$ Thus, it is better to use aliphatic ammonium cations, which are tolerant to the nucleophilic regents.6) Accordingly, BMPTFSI was used for the operation test of the fuel cell as described below.

The membrane-electrode assemblies (MEAs) were prepared by using the Nafion membrane impregnated with an ionic liquid and the carbon papers spread with Pt-loaded carbon. However, it was difficult to obtain reproducible results by these MEAs. Thus, Pt mesh electrodes (100 mesh) were used as the anode and cathode in order to make the three-phase zone while the electrode area became very small compared with normal gas-diffusion electrodes. It was verified that the current between two Pt mesh electrodes attached to $\mathrm{H} 2 \mathrm{O} / \mathrm{Nafon}$ was as small as $\sim 1 \mu \mathrm{A} \mathrm{cm}{ }^{-2}$ when a DC voltage of $500 \mathrm{mV}$ was applied under humidificated (R.H. $=100 \%$ ) hydrogen atmosphere at $80^{\circ} \mathrm{C}$.

Figure 8 shows the current observed in the fuel cell using BMPTFSI/Nafion when a constant voltage was applied between the anode and cathode with feeding dry hydrogen to both electrodes at $120^{\circ} \mathrm{C}$. The current density was calculated by the geometric area of Pt mesh electrode $\left(5 \mathrm{~cm}^{2}\right)$. The current decayed with time and finally reached to a constant value after $\sim 25$ minutes. The identical curves were obtained when the applied voltage exceed $300 \mathrm{mV}$. The observed current decay can be explained by the growth of the diffusion layer at the electrodes as described in §3.3. The constant current is probably corresponding to the limiting current for the reduction of HTFSI at the cathode. Figure 9 shows the cell voltage in the fuel cell with feeding dry hydrogen and oxygen to the anode and cathode, respectively, at $120^{\circ} \mathrm{C}$. Under an open circuit condition, the cell voltage was constant for over 30 minutes. When the current was regulated below $4.8 \mu \mathrm{A} \mathrm{cm}$, the cell voltage decayed with time and finally reached to a constant value, as observed in Fig. 8. However, the cell voltage decayed monotonously to $0 \mathrm{~V}$ when the current exceed $6.0 \mu \mathrm{A}$ $\mathrm{cm}^{-2}$, probably because the current was close to the limiting current. The overvoltages at the anode and cathode were measured with use of a reference electrode, as shown in Fig. 10. The overvoltage at the anode is small, indicating the oxidation of hydrogen to HTFSI is facile at platinum. On the other hand, the overvoltage at the cathode is larger and more sensitive to the current than that at the anode. Since the reproducible results were obtained at intervals of 1 hour, the overvoltage is unlikely to be ascribed to the degradation of the components of 


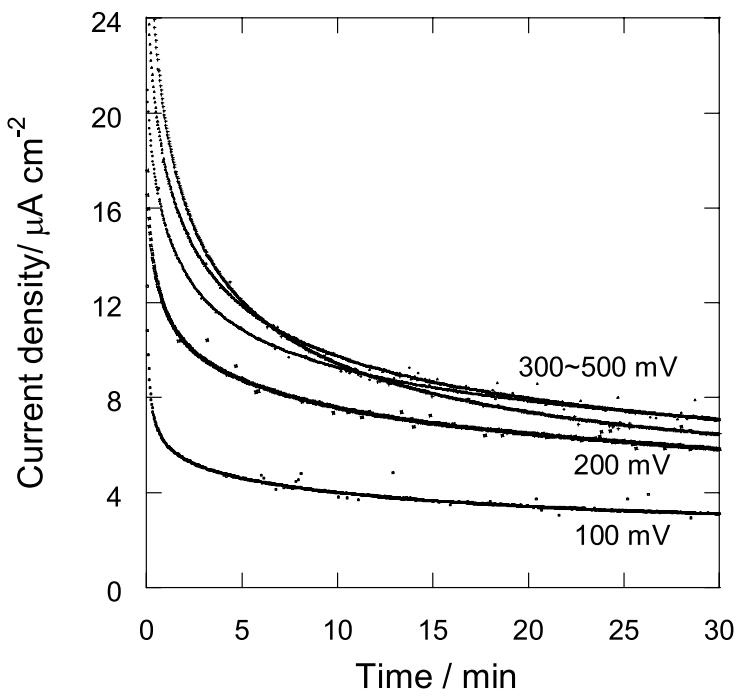

Fig. 8 Direct current observed during potentiostatic polarization for BMPTFSI/Nafion $\left(X_{\mathrm{IL}}=0.95 \mathrm{mmol} \mathrm{g}^{-1}\right)$ under dry hydrogen atmosphere at $120^{\circ} \mathrm{C}$.

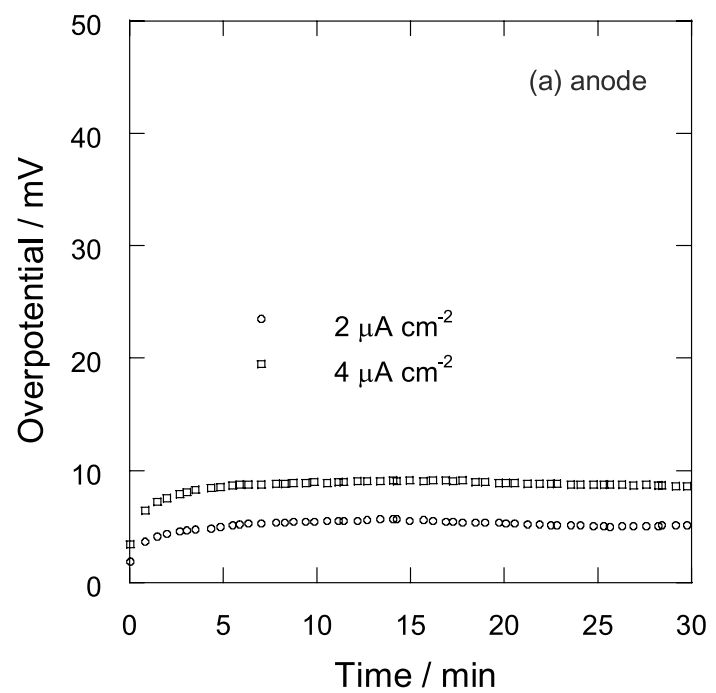

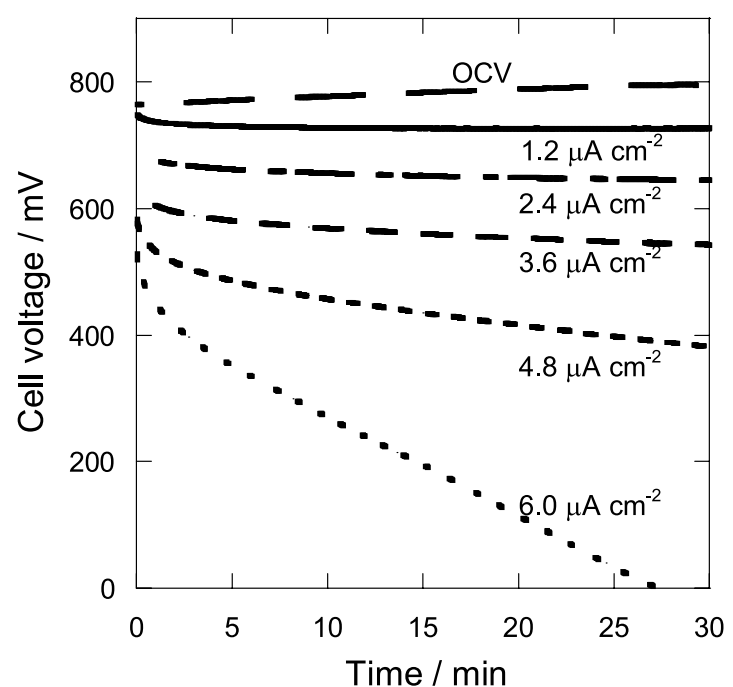

Fig. 9 Cell voltages of the fuel cell using BMPTFSI/Nafion $\left(X_{\mathrm{IL}}=0.95 \mathrm{mmol} \mathrm{g}^{-1}\right)$ at $120^{\circ} \mathrm{C}$. Dry $\mathrm{H}_{2}$ and $\mathrm{O}_{2}$ were fed to the anode and cathode, respectively.

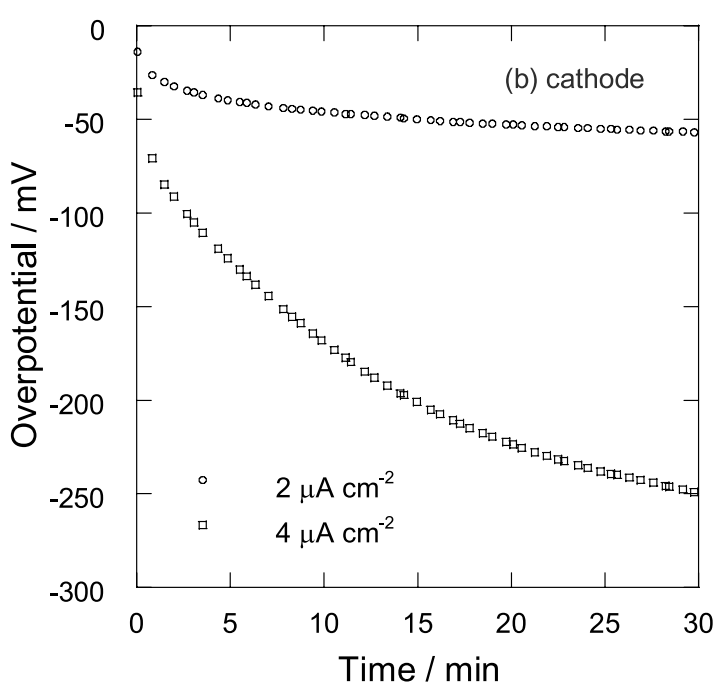

Fig. 10 Overpotential of the (a) anode and (b) cathode of the fuel cell using the BMPTFSI/Nafion $\left(X_{\mathrm{IL}}=0.95 \mathrm{mmol} \mathrm{g}^{-1}\right)$ at $120^{\circ} \mathrm{C}$. Dry $\mathrm{H}_{2}$ and $\mathrm{O}_{2}$ were fed to the anode and cathode, respectively.

the cell. Taking account of the fact that the overpotential increased with time as observed in Fig. 8, it is suggested that the large overvoltage at the cathode is attributed to not only the sluggish reduction of oxygen but also the slow transport of HTFSI.

\section{Conclusion}

It was found that the membranes impregnated with $\mathrm{TFSI}^{-}$-based ionic liquids can be used up to $200^{\circ} \mathrm{C}$. The transportation of proton in the membranes was confirmed under dry hydrogen atmosphere above $100{ }^{\circ} \mathrm{C}$ without humidification. The apparent ionic conductivity of the membranes reached to $10^{-2} \mathrm{~S} \mathrm{~cm}^{-1}$ at $200{ }^{\circ} \mathrm{C}$. However, the apparent ionic conductivity is not regarded as the proton conductivity since the transportation of protons in the membranes is considered to be achieved by the diffusion of neutral HTFSI and migration of TFSI ${ }^{-}$. The fuel cell using the membrane could be operated continuously for more than 30 minutes at $120{ }^{\circ} \mathrm{C}$ with feeding dry hydrogen and oxygen to the anode and cathode, respectively. However, the decay of the cell voltage was observed when the current was close to the limiting current caused by the slow diffusion of HTFSI. There are possibilities to prepare superior membranes based on other polymer electrolytes with ionic liquids. However, in order to apply the membranes impregnated with ionic liquids for practical use, it is necessary to develop fundamental techniques suitable to these membranes, such as the preparation of MEAs and catalyst layers. 


\section{Acknowledgement}

The present work was financially supported by a Grant-in-Aid for Scientific Research on Priority Areas B of "New Technologies of DMFC" no. 13134201 from the Ministry of Education, Culture, Sports, Science, and Technology, Japan MEXT. This work was also supported by a Grant-in-Aid for the 21st Century COE program "KEIO Life Conjugate Chemistry" from MEXT. The authors also thank Kanto Denka Kogyo for providing LiTFSI.

\section{References}

1) Y. Sone, P. Ekdunge, and D. Simonsson, J. Electrochem. Soc., 143, 1254 (1996).

2) J. Fuller and R. T. Carlin, in Molten Salts XII, P. C, Trulove, H. C. De Long, G. R. Stafford and S. Deki eds., PV99-41, p.27, The Electochemical Society Proceedings Series, Pennington, NJ (2000).

3) M. Doyle, S. K. Choi, and G. Proulx, J. Electrochem. Soc., 147, 34 (2000).

4) J. Sun, M. R. Jordan, M. Forsyth, and D. R. MacFarlane, Electrochem. Acta, 46, 1703 (2001).
5) Y. Katayama, H. Onodera, M. Yamagata, and T. Miura, J. Electrochem. Soc., 151, A59 (2004).

6) Y. Katayama, K. Sekiguchi, M. Yamagata, and T. Miura, J. Electrochem. Soc., 152, E247 (2005).

7) J. Surowiec and R. Bogoczec, J. Thermal. Anal., 33, 1097 (1988).

8) P. Bonhôte, A. Dias, N. Papageorgiou, K. Kalyanasundaram, and M. Graltzel, Inorg. Chem., 35, 1168 (1996).

9) D. R. MacFarlane, P. Meakin, J. Sun, N. Amini, and M. Forsyth, J. Phys. Chem. B, 103, 4164 (1999).

10) J. Sun, M. Forsyth and D. R. MacFarlane, J. Phys. Chem. $B$, 102, 8858 (1998).

11) C. M. Gordon and A. J. McLean, Chem. Commun., 2000, 1395.

12) S. N. Baker, G. A. Baker, M. A. Kane, and F. V. Bright, J. Phys. Chem. B, 105, 9663 (2001).

13) J. E. L. Dullius, P. A. Z. Suarez, S. Einloft, R. F. de Souza, and J. Dupont, Organometallics, 17, 815 (1998).

14) M. Mizuhata, K. Yaso, Y. Ito, and S. Deki, Electrochemistry, 73, 606 (2005). 